\title{
Association of HLA-B*41:02 with Henoch-Schönlein Purpura (IgA Vasculitis) in Spanish individuals irrespective of the HLA-DRB1 status
}

\author{
Raquel López-Mejías ${ }^{1 \dagger}$, Fernanda Genre ${ }^{1 \dagger}$, Belén Sevilla Pérez ${ }^{2 \dagger}$, Santos Castañeda ${ }^{3}$, Norberto Ortego-Centeno ${ }^{2}$,

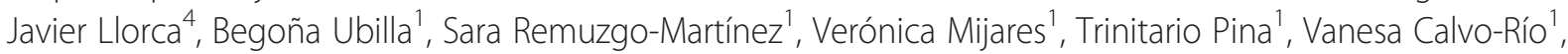 \\ Ana Márquez ${ }^{5}$, José A Miranda-Filloy ${ }^{6}$, Antonio Navas Parejo ${ }^{7}$, Marta Conde-Jaldón ${ }^{8}$, Lourdes Ortiz-Fernández ${ }^{8}$, \\ Diego Argila ${ }^{9}$, Maximiliano Aragües ${ }^{9}$, Esteban Rubio ${ }^{10}$, Manuel León Luque ${ }^{10}$, Juan María Blanco-Madrigal ${ }^{11}$, \\ Eva Galíndez-Aguirregoikoa ${ }^{11}$, Francisca González Escribano ${ }^{8}$, J Gonzalo Ocejo-Vinyals ${ }^{12}$, Javier Martín ${ }^{13}$, \\ Ricardo Blanco ${ }^{1}$ and Miguel A González-Gay ${ }^{1 *}$
}

\begin{abstract}
Introduction: A study was conducted to determine whether the human leukocyte antigen (HLA) B alleles are implicated in the susceptibility to Henoch-Schönlein purpura (HSP) in the largest series of Caucasian HSP patients ever assessed for genetic studies.

Methods: The study population was composed of 349 Spanish patients diagnosed with HSP fulfilling the American College of Rheumatology and the Michel et al. classification criteria, and 335 sex and ethnically matched controls. HLA-B phenotypes were determined by sequencing-based typing (SBT) and analyzed by chi-square or Fisher exact test.

Results: A statistically significant increase of HLA-B*41:02 allele in HSP patients when compared with controls was found ( $8.3 \%$ versus $1.5 \%$ respectively; $P=0.0001 ; O R$ (odds ratio) $=5.76$ [2.15-19.3]). These results remained statistically significant after adjusting for Bonferroni correction $(P=0.0028)$. An internal validation also confirmed the susceptibility effect on HSP associated with HLA-B*41:02 (OR $=5.70$ [1.98-16.44]). Since a former study described an association between HLA-DRB1*01:03 and HSP susceptibility, we also evaluated the implication of HLA-B*41:02 independently of HLA-DRB1*01:03. Interestingly, the association remained statistically significant $(P=0.0004, \mathrm{OR}=4.97$ [1.8-16.9]). No $H L A-B$ association with specific HSP clinical features was found.
\end{abstract}

Conclusions: Our study indicates that HLA-B*41:02 is associated with the susceptibility to HSP in Spanish patients irrespective of HLA-DRB1 status.

\section{Introduction}

Henoch-Schönlein purpura (HSP), also called immunoglobulin-A (IgA) vasculitis, is a leukocytoclastic vasculitis characterized by IgA dominant immune deposits involving mainly the skin but other tissues as well. HSP is more common in children but it is not exceptional in adults [1]. The main feature of this vasculitis is a palpable purpura

\footnotetext{
* Correspondence: miguelaggay@hotmail.com

${ }^{\dagger}$ Equal contributors

${ }^{1}$ Epidemiology, Genetics and Atherosclerosis Research Group on Systemic Inflammatory Diseases, Rheumatology Division, Hospital Universitario

Marqués de Valdecilla, IDIVAL, Santander, Spain

Full list of author information is available at the end of the article
}

involving predominantly the lower extremities. Besides skin involvement, HSP often causes joint pain and gastrointestinal complications [2]. Renal manifestations may also be observed in HSP patients, mainly in adults, indicating a poor prognosis of this disorder [2].

HSP has a multifactorial pathology in which a wide variety of pathogens, drugs, and other environmental exposures have been involved [3]. Furthermore, several studies have revealed the relevant role of some genetic variants (including those located in the human leukocyte antigen (HLA) system [4]) in both susceptibility and HSP clinical heterogeneity.

The HLA region includes a group of genes located in chromosome $6(6 \mathrm{p} 21)$ that encodes for proteins on the 
surface of cells that are responsible for regulation of the immune system in humans [5]. HLA has been described as a common genetic component that underlies immunemediated diseases [6], being associated with more diseases than any other region of the human genome [5]. In this regard, the association between class II $H L A$ genes and HSP susceptibility in Caucasians has been well-established in a recent well-powered study [4]. In this work, the susceptibility effect of $H L A-D R B 1 * 01$ (mainly due to $H L A$ $D R B 1 * 01: 03$ allele) was confirmed, whereas a potential protective effect of $H L A-D R B 1 * 03$ (mainly due to $H L A$ $D R B 1 * 03: 01$ allele) was also postulated [4]. However, the influence of class I HLA genes in HSP Caucasian patients still remains unclear since only a few studies, performed in small cohorts of HSP patients, have addressed this issue [7-10]. Although no association between class I $H L A$ ( $H L A-A, H L A-B$, and $H L A-C$ ) genes and HSP was found by Ostergaard et al. [10], $H L A-B * 35$ allele has been suggested to be a potential marker of renal complications secondary to HSP by Nathwani et al., Nyulassy et al. and Amoli et al. [7-9].

Taken together these considerations prompted us to investigate the potential implication of $H L A-B$ gene in the susceptibility to HSP. For this purpose we took advantage of the largest series of Caucasian patients with this vasculitis ever assessed for genetic studies.

\section{Methods}

Patients and study protocol

A series of 349 Spanish patients with cutaneous vasculitis who fulfilled Michel et al. [11]. classification criteria for HSP were included in the present study. According to these criteria, they were classified as having HSP if they fulfilled three or more of the following characteristics: palpable purpura, bowel angina, gastrointestinal bleeding, macroscopic or microscopic hematuria, age at disease onset $\leq 20$ years, and no previous history of medications prior to the onset of the disease. Also, all patients included in this series were required to fulfill the American College of Rheumatology classification criteria for HSP [12]. Blood samples were obtained from patients recruited from Hospital Universitario Lucus Augusti (Lugo), Hospital Universitario Marqués de Valdecilla (Santander), Hospital Universitario La Princesa (Madrid), Hospital Universitario San Cecilio (Granada), Hospital Universitario Virgen del Rocío (Sevilla) and Hospital Universitario de Basurto (Bilbao). Information on the main clinical features of the whole series of 349 HSP Spanish patients recruited in this study is shown in Table 1. Hematuria with or without proteinuria and severe gastrointestinal manifestations were frequently observed in these patients. However, only 24 of the 349 patients $(6.8 \%)$ had persistent renal involvement (renal sequelae) at last follow-up.

A set of 335 sex and ethnically matched controls without history of cutaneous vasculitis or any other autoimmune disease comprising blood donors from the National DNA Bank Repository (Salamanca, Spain), was also included in the study.

A subject's written consent was obtained according to the declaration of Helsinki, and the study was approved by the Ethics Committees of Galicia for Hospital Universitario Lucus Augusti, of Cantabria for Hospital

Table 1 Main clinical features of a series of 349 Spanish patients with HSP

\begin{tabular}{|c|c|}
\hline Main characteristics & $\%(n / N)$ \\
\hline Children (age $\leq 20$ years)/adults (age $>20$ years) & $283 / 66$ \\
\hline Male/female & $176 / 173$ \\
\hline \multicolumn{2}{|l|}{ Age at the onset of the disease (years) } \\
\hline mean $\pm S D$ & $14.8 \pm 18.0$ \\
\hline median (IQR) & 7 (5 to 18$)$ \\
\hline Duration of follow-up (years, mean \pm SD) & $3.3 \pm 4.3$ \\
\hline Palpable purpura and/or maculopapular rash & $100(349 / 349)$ \\
\hline Arthralgia and/or arthritis & $56.4(197 / 349)$ \\
\hline Gastrointestinal manifestations (if 'a' and/or 'b') & $53.6(187 / 349)$ \\
\hline a) Bowel angina & $52.1(182 / 349)$ \\
\hline b) Gastrointestinal bleeding & $16.0(56 / 349)$ \\
\hline Renal manifestations (if any of the following characteristics) & $35.5(124 / 349)$ \\
\hline a) Hematuria & $34.6(121 / 349)$ \\
\hline b) Proteinuria & $32.9(115 / 349)$ \\
\hline c) Nephrotic syndrome & $4.3(15 / 349)$ \\
\hline d) Renal sequelae (persistent renal involvement) ${ }^{a}$ & $6.8(24 / 349)$ \\
\hline
\end{tabular}

${ }^{a}$ At last follow-up. HSP: Henoch-Schönlein purpura; SD: standard deviation; IQR: interquartile range. 
Universitario Marqués de Valdecilla, of Madrid for Hospital Universitario La Princesa, of Andalucía for Hospital Universitario San Cecilio and Hospital Universitario Virgen del Rocío, and of País Vasco for Hospital Universitario de Basurto.

\section{Genotyping}

High-molecular-weight genomic DNA was extracted from whole blood using the QIAamp DNA Blood Mini Kit (Qiagen, Hilden, Germany) according to the manufacturer's instructions.

All DNA samples were stored at $-20^{\circ} \mathrm{C}$ until the HLA analysis. Class I $H L A B$ locus high-resolution typing was performed through sequencing-based typing (SBT), by using the SBTexcellerator Kit and analyzed with the SBTengine ${ }^{\circ}$-SBT HLA typing software (GenDx, Utrecht, The Netherlands) following the manufacturer's instructions.

Positive controls were used to ensure the quality control for the genotyping procedures. These samples, of known sequence, were obtained from External Proficiency Testing Programs (GECLID - Spanish Society of Immunology), following the European Federation of Immunogenetics standards. Additionally, negative controls were included to discard the effect of DNA contamination.

\section{Statistical analysis}

Continuous data are described as mean and standard deviation (mean $\pm \mathrm{SD}$ ) and categorical variables as percentages.

The strength of association between HSP and $H L A-B$ phenotypes was estimated using odds ratios (OR) and 95\% confidence intervals (CI). Levels of significance were determined using contingency tables by either the chi-square test or Fisher exact (expected values below 5) analysis. Results were adjusted for Bonferroni correction. To obtain an internal validation, we carried out a bootstrap test with 1,000 replications.

All analyses were performed with STATA statistical software 12/SE (Stata Corp., College Station, TX, USA).

The linkage disequilibrium between HLA alleles was calculated using the PLINK software [13].

\section{Results}

When HSP patients were compared with matched controls, some differences in $H L A-B$ phenotype frequencies were observed (Table 2). In this regard, the $H L A-B^{*} 41$ phenotype was significantly increased in HSP patients compared to controls (10.1\% versus $3.3 \%$, respectively; $P=0.0007$; $\mathrm{OR}=$ 3.18 (1.53 to 7.07$)$ ). This association was mainly due to the $H L A-B * 41: 02$ allele (8.3\% in HSP patients versus $1.5 \%$ in controls; $P=0.0001$; $\mathrm{OR}=5.76(2.15$ to 19.3$))$ and remained statistically significant after adjusting for Bonferroni correction $(P=0.0028)$ (Table 2). Since the potential effect of $H L A-B * 41: 02$ on HSP had not previously been reported, we carried out a bootstrapping procedure that confirmed the susceptibility effect on HSP associated with $H L A-B * 41: 02$ $(\mathrm{OR}=5.70$ (1.98 to 16.44$))$. However, no statistically significant results were observed regarding other $H L A-B$ phenotypes and HSP susceptibility (Table 2).

Since in a recent study we disclosed an association between HLA-DRB1*01:03 and HSP susceptibility [4], we also evaluated whether the implication of $H L A-B^{*} 41: 02$ was independent of the HLA-DRB1*01:03 status (Table 3). Interestingly, and as shown in Table 3 , the association of $H L A-B * 41: 02$ with HSP susceptibility remained statistically significant irrespective of $H L A-D R B 1 * 01: 03$ $(P=0.0004$, OR $=4.97$ (1.8 to 16.9$))$ (Table 3). To further confirm the independence of both alleles, we calculated the linkage disequilibrium between them in our study population. As expected, the $r^{2}$ value showed that both alleles were independent $\left(r^{2}=0.003\right)$.

In a further step we assessed whether $H L A-B$ phenotype differences might exist according to specific features of the disease, such as age at disease onset before and after 20 years, presence of joint, gastrointestinal or renal manifestations. In this regard, we did not observe any trend toward significance between different $H L A-B$ phenotypes and gastrointestinal manifestations. Regarding age at disease diagnosis, we only found a statistically marginal increase in the frequency of adults $(>20$ years old) carrying the $H L A-B * 45: 01$ allele. However, this marginal significance was lost after Bonferroni correction. A statistically significant increase in $H L A-B^{*} 14: 02$ and 53:01 was detected in HSP patients with renal manifestations $(P=0.0113$ and 0.0415 , respectively). However, similarly to the previous case, when we corrected these results by Bonferroni, this significance was lost.

Finally, 12 HSP patients with renal manifestations carried the $H L A-B * 41: 02$ allele. However, no statistically significant association was observed between the presence of this $H L A-B$ allele and the presence of renal manifestations $(P=0.513$; OR $=1.31(0.53$ to 3.17$))$.

\section{Discussion}

The vasculitides constitute a heterogeneous group of diseases that have in common the presence of inflammation of the blood vessels $[1,14]$. Their complex etiology is far from being completely elucidated. Both environmental and genetic factors appear to influence the development and progression of these conditions, HLA being the main genetic factor related to these diseases. Although the effect of the class II $H L A$ genes in the susceptibility of HSP in Caucasians has recently been characterized [4], there is scarce information on the potential implication of class I HLA genes in HSP [7-10]. Because of that, we have performed a study to provide evidence of the potential implications of the $H L A-B$ gene in the susceptibility to HSP. For this purpose, we recruited the largest series of Caucasian patients with this 
Table 2 HLA-B phenotype frequencies in patients with HSP and controls

\begin{tabular}{|c|c|c|c|c|c|}
\hline$H L A-B$ & & Patients with HSP (number $=349$ ) & Controls (number $=335$ ) & $P$ & OR $(95 \% \mathrm{Cl})$ \\
\hline$B^{*} 07$ & $B^{*} 07: 02$ & $52(14.9)$ & $49(14.6)$ & 0.92 & $1.02(0.65$ to 1.60$)$ \\
\hline$B^{*} 08$ & $B^{*} 08: 01$ & $29(8.3)$ & $31(9.2)$ & 0.66 & $0.88(0.50$ to 1.56$)$ \\
\hline$B^{*} 13$ & $B^{*} 13: 02$ & $7(2.0)$ & $8(2.4)$ & 0.73 & $0.84(0.25$ to 2.67$)$ \\
\hline \multirow[t]{2}{*}{$B^{*} 14$} & $B^{*} 14: 01$ & $8(2.3)$ & $5(1.5)$ & 0.44 & $1.54(0.44$ to 6.07$)$ \\
\hline & $B^{*} 14: 02$ & $29(8.3)$ & $47(14.0)$ & 0.017 & 0.55 (0.33 to 0.93 ) \\
\hline \multirow[t]{2}{*}{$B^{*} 15$} & $B^{*} 15: 01$ & $25(7.2)$ & $22(6.6)$ & 0.76 & $1.10(0.58$ to 2.10$)$ \\
\hline & $B^{*} 15: 17$ & $4(1.2)$ & $5(1.5)$ & 0.69 & 0.76 (0.15 to 3.60$)$ \\
\hline$B^{*} 18$ & $B^{*} 18: 01$ & $36(10.3)$ & $41(12.2)$ & 0.42 & 0.82 (0.49 to 1.36$)$ \\
\hline$B^{*} 27$ & $B * 27: 05$ & $20(5.9)$ & $20(6.0)$ & 0.89 & $0.96(0.48$ to 1.91$)$ \\
\hline \multirow[t]{2}{*}{$B^{*} 35$} & $B^{*} 35: 01$ & $50(14.3)$ & $51(15.2)$ & 0.74 & 0.93 (0.59 to 1.45 ) \\
\hline & $B * 35: 03$ & $20(5.7)$ & $8(2.4)$ & 0.027 & $2.48(1.02$ to 6.61$)$ \\
\hline$B^{*} 38$ & $B^{*} 38: 01$ & $10(3.0)$ & $27(8.1)$ & 0.0027 & 0.34 (0.14 to 0.73 ) \\
\hline$B^{*} 39$ & $B * 39: 01$ & $8(2.4)$ & $7(2.1)$ & 0.85 & 1.10 (0.34 to 3.61$)$ \\
\hline \multirow[t]{2}{*}{$B^{*} 40$} & $B * 40: 01$ & $16(4.6)$ & $17(5.1)$ & 0.76 & 0.89 (0.42 to 1.93 ) \\
\hline & $B * 40: 02$ & $10(3.0)$ & $5(1.5)$ & 0.22 & 1.94 (0.59 to 7.33$)$ \\
\hline \multirow[t]{2}{*}{$B^{*} 41^{\mathrm{a}}$} & $B^{*} 41: 01$ & $6(1.8)$ & $6(1.8)$ & 0.94 & 0.95 (0.25 to 3.62) \\
\hline & $B * 41: 02$ & $28(8.3)$ & $5(1.5)$ & 0.0001 & 5.76 (2.15 to 19.3$)$ \\
\hline \multirow[t]{2}{*}{$B^{*} 44$} & $B^{*} 44: 02$ & $35(10.0)$ & $16(4.8)$ & 0.009 & 2.22 (1.17 to 4.39$)$ \\
\hline & $B^{*} 44: 03$ & $61(17.5)$ & $71(21.2)$ & 0.22 & 0.79 (0.53 to 1.17$)$ \\
\hline$B^{*} 45$ & $B * 45: 01$ & $7(2.0)$ & $11(3.3)$ & 0.29 & 0.60 (0.19 to 1.73 ) \\
\hline$B^{*} 49$ & $B * 49: 01$ & $24(7.2)$ & $34(10.1)$ & 0.12 & 0.65 (0.36 to 1.16$)$ \\
\hline$B * 50$ & $B * 50: 01$ & $26(7.7)$ & $16(4.8)$ & 0.14 & 1.60 (0.81 to 3.26$)$ \\
\hline$B * 51$ & $B * 51: 01$ & $53(15.2)$ & $56(16.7)$ & 0.59 & 0.89 (0.58 to 1.37 ) \\
\hline$B * 52$ & $B * 52: 01$ & $5(1.5)$ & $11(3.3)$ & 0.11 & 0.43 (0.11 to 1.35$)$ \\
\hline$B * 53$ & $B * 53: 01$ & $12(3.6)$ & $13(3.9)$ & 0.76 & 0.88 (0.36 to 2.13 ) \\
\hline$B * 55$ & $B * 55: 01$ & $4(1.2)$ & $12(3.6)$ & 0.035 & 0.31 (0.07 to 1.04 ) \\
\hline$B * 57$ & $B * 57: 01$ & $22(6.3)$ & $12(3.6)$ & 0.10 & 1.81 (0.84 to 4.10$)$ \\
\hline$B * 58$ & $B^{*} 58: 01$ & $13(3.7)$ & $11(3.3)$ & 0.75 & 1.14 (0.46 to 2.85 ) \\
\hline
\end{tabular}

${ }^{a} 10.1 \%$ in HSP patients versus $3.3 \%$ in controls; $P=0.0007 ; O R=3.18$ (1.53 to 7.07); values are expressed as number $(\mathrm{n})$ and percentages (\%); the result that remained statistically significant after adjusting for Bonferroni correction ( $\mathrm{p}_{\mathrm{BNF}}=0.0028$ ) is highlighted in bold. HLA: human leukocyte antigen; HSP: Henoch- Schönlein purpura; OR: odds ratio; $\mathrm{Cl}$ : confidence interval.

vasculitis ever assessed for genetic studies. Accordingly, our findings support the role of the $H L A-B * 41: 02$ as a susceptibility marker of this disease irrespective of HLA-DRB1 status. However, in contrast to previous studies [7-9], we could not confirm an association between $H L A-B$ alleles and renal manifestations or any other specific features of this vasculitis. In this regard, considering that our analysis was performed in a wellpowered cohort of HSP patients, we cannot exclude the possibility that previous results might have been the result of a type I error. Because of that, additional studies including large series of patients are needed to fully establish the association of the $H L A-B$ locus with specific features of HSP.

Table $3 H L A-B * 41: 02$ and $H L A-D R B 1 * 01: 03$ are independently associated with increased susceptibility to HSP

\begin{tabular}{llllr}
\hline HLA-DRB1*01:03 & HLA-B*41:02 & Patients with HSP & Controls & OR (95\% CI) \\
\hline- & - & 270 & 292 & Ref. \\
- & + & 23 & 5 & 0.0004 \\
+ & - & 48 & 6 & $<.97(1.8$ to 16.9$)$ \\
+ & + & 1 & 0 & $8.65(3.6$ to 25.1$)$ \\
\hline
\end{tabular}

HLA: human leukocyte antigen; HSP: Henoch- Schönlein purpura; OR: odds ratio; Cl: confidence interval. 
Class I HLA molecules have previously been associated with different types of primary systemic vasculitis in Caucasians. An association of $H L A-B * 15, H L A-B * 8$, $H L A-C w 3$ and $H L A-C w 6$ with giant cell arteritis (a large-sized blood vessel vasculitis) has been reported [15-17]. Although the involvement of class I HLA genes in Kawasaki disease (a vasculitis involving mediumsized blood vessels) is controversial, $H L A-B * 51$ and $H L A-B * 44$ have been proposed to be associated with this disease $[18,19]$. Additionally, $H L A-B * 50$ has been shown to be related to susceptibility to granulomatosis with polyangiitis, a small-sized vessel anti-neutrophil cytoplasmic antibody-associated vasculitis [20]. Finally, a recently published analysis of imputed genome wide association study data described an association between a genetic variant located between the $H L A-B$ and MICA loci and Behçet's disease [21]. Regarding $H L A-B * 35: 03$, other authors reported an increase of this allele in overall HSP [22]. Even if in our study we observed a significantly increased frequency of this allele in our HSP cohort, this significance was lost after Bonferroni correction. However, this lack of significance after correction in our study might be due to sample size or also to differences between our cohort and that studied by Peru et al. [22].

\section{Conclusions}

The analysis of our data supports an association of HLA$B^{*} 41: 02$ with susceptibility to HSP in Caucasians, irrespective of $H L A-D R B 1$ status. These results may have potential clinical implications as they may help to better identify individuals at risk for this vasculitis.

\section{Abbreviations}

Cl: confidence interval; HLA: Human Leukocyte Antigen; HSP:

Henoch-Schönlein purpura; IgA: immunoglobulin-A; IQR: interquartile range; OR: odds ratio; SBT: sequencing-based typing; SD: standard deviation.

\section{Competing interests}

The authors declare that they have no competing interests.

\section{Authors' contributions}

RLM, FG and BSP participated in the design of the study, data analysis and helped to draft the manuscript. SC, NOC and JM have been involved in the acquisition and interpretation of data and in revising it critically for important intellectual content. JL carried out the analysis and interpretation of the data, and helped to draft and revise the final manuscript. BU, SR-M, VM, TP, VC-R, AM, JAMF, ANP, DA, MA, ER, MLL, JMB-M and EG-A participated in the acquisition and interpretation of data and helped to draft the manuscript. MC-J, LO-F, FGE and JGO-V carried out genotyping and helped to draft the manuscript. RB and MAG-G made substantial contributions to conception and design of the study, acquisition of data, coordination and helped to draft the manuscript and have given final approval of the version to be published. All authors agree to be accountable for all aspects of the work in ensuring that questions related to the accuracy or integrity of any part of the work are appropriately investigated and resolved. All authors have read and approved the final manuscript.

\section{Authors' information}

Drs Gonzalez-Gay and Blanco shared senior authorship in this study.

\section{Acknowledgements}

We wish to thank all the patients with HSP and controls who participated to make this study possible. We want to specially thank Patricia Fuentevilla Rodríguez, María Del Camino Villa Llamazares and María Eugenia Cuadrado Mantecón for their technical assistance. This study was supported by a grant from 'Fondo de Investigaciones Sanitarias' PI12/00193 (Spain). RLM is a recipient of a Sara Borrell postdoctoral fellowship from the Instituto de Salud Carlos III at the Spanish Ministry of Health (Spain) (CD12/00425). FG and BU are supported by funds from the RETICS Program (RIER) (RD12/0009/0013).

\section{Author details}

${ }^{1}$ Epidemiology, Genetics and Atherosclerosis Research Group on Systemic Inflammatory Diseases, Rheumatology Division, Hospital Universitario Marqués de Valdecilla, IDIVAL, Santander, Spain. ${ }^{2}$ Medicine Department, Hospital Universitario San Cecilio, Granada, Spain. ${ }^{3}$ Rheumatology Department, Hospital Universitario La Princesa, IIS-Princesa, Madrid, Spain. ${ }^{4}$ Epidemiology and Computational Biology Department, School of Medicine, University of Cantabria, and CIBER Epidemiología y Salud Pública (CIBERESP), IDIVAL, Santander, Spain. ${ }^{5}$ Institute of Parasitology and Biomedicine López-Neyra (IPBLN-CSIC) and Systemic Autoimmune Diseases Unit, Hospital Clínico San Cecilio, Granada, Spain. ${ }^{6}$ Division of Rheumatology, Hospital Universitario Lucus Augusti, Lugo, Spain. ${ }^{7}$ Nephrology Department, Hospital Universitario San Cecilio, Granada, Spain. ${ }^{8}$ Immunology Department, Hospital Universitario Virgen del Rocío, Sevilla, Spain. ${ }^{9}$ Dermatology Department, IIS-IP, Hospital de la Princesa, Madrid, Spain. ${ }^{10}$ Rheumatology Department, Hospital Universitario Virgen del Rocío, Sevilla, Spain. ${ }^{11}$ Rheumatology Department, Hospital Universitario de Basurto, Bilbao, Spain. ${ }^{12}$ Immunology Department, Hospital Universitario Marqués de Valdecilla, Santander, Spain. ${ }^{13}$ Institute of Parasitology and Biomedicine López-Neyra, CSIC, Granada, Spain.

Received: 15 January 2015 Accepted: 8 April 2015

Published online: 14 April 2015

\section{References}

1. González-Gay MA, García-Porrúa C. Epidemiology of the vasculitides. Rheum Dis Clin North Am. 2001;27:729-49.

2. García-Porrúa C, Calviño MC, Llorca J, Couselo JM, González-Gay MA. Henoch-Schönlein purpura in children and adults: clinical differences in a defined population. Semin Arthritis Rheum. 2002;32:149-56.

3. Wyatt RJ, Julian BA. IgA nephropathy. N Engl J Med. 2013;368:2402-14.

4. López-Mejías R, Genre F, Pérez BS, Castañeda S, Ortego-Centeno N, Llorca J, et al. HLA-DRB1 association with Henoch-Schonlein purpura. Arthritis Rheumatol. 2015;67:823-7.

5. Complete sequence and gene map of a human major histocompatibility complex. The MHC sequencing consortium. Nature. 1999:401:921-3.

6. Klein J, Sato A. The HLA system, second of two parts. N Engl J Med. 2000;343:782-6.

7. Amoli MM, Thomson W, Hajeer AH, Calviño MC, Garcia-Porrua C, Ollier WE, et al. HLA-B35 association with nephritis in Henoch-Schonlein purpura. J Rheumatol. 2002;29:948-9.

8. Nathwani D, Laing RB, Smith CC, Edward N. Recurrent post-infective Henoch-Schonlein syndrome: a genetic influence related to HLA B35? J Infect. 1992;25:205-10.

9. Nyulassy S, Buc M, Sasinka M, Pavlovic M, Slugen I, Hirschová V, et al. The HLA system in glomerulonephritis. Clin Immunol Immunopathol. 1977;7:319-23.

10. Ostergaard JR, Storm K, Lamm LU. Lack of association between HLA and Schoenlein-Henoch Purpura. Tissue Antigens. 1990;35:234-5.

11. Michel BA, Hunder GG, Bloch DA, Calabrese LH. Hypersensitivity vasculitis and Henoch-Schonlein purpura: a comparison between the 2 disorders. J Rheumatol. 1992;19:721-8.

12. Mills JA, Michel BA, Bloch DA, Calabrese LH, Hunder GG, Arend WP, et al. The American College of Rheumatology 1990 criteria for the classification of Henoch-Schonlein purpura. Arthritis Rheum. 1990;33:1114-21.

13. Purcell $S$, Neale B, Todd-Brown K, Thomas L, Ferreira MA, Bender D, et al. PLINK: a tool set for whole-genome association and population-based linkage analyses. Am J Hum Genet. 2007;81:559-75.

14. Jennette JC, Falk RJ, Bacon PA, Basu N, Cid MC, Ferrario F, et al. 2012 revised International Chapel Hill Consensus Conference Nomenclature of Vasculitides. Arthritis Rheum. 2013;65:1-11. 
15. Armstrong RD, Behn A, Myles A, Panayi GS, Welsh Kl. Histocompatibility antigens in polymyalgia rheumatica and giant cell arteritis. J Rheumatol. 1983;10:659-61.

16. Gonzalez-Gay MA, Rueda B, Vilchez JR, Lopez-Nevot MA, Robledo G, Ruiz $M P$, et al. Contribution of MHC class I region to genetic susceptibility for giant cell arteritis. Rheumatology (Oxford). 2007:46:431-4.

17. Kemp A, Marner K, Nissen SH, Heyn J, Kissmeyer-Nielsen F. HLA antigens in cases of giant cell arteritis. Acta Ophthalmol (Copenh). 1980;58:1000-4

18. Kaslow RA, Bailowitz A, Lin FY, Koslowe P, Simonis T, Israel E. Association of epidemic Kawasaki syndrome with the HLA-A2, B44, Cw5 antigen combination. Arthritis Rheum. 1985;28:938-40.

19. Krensky AM, Berenberg W, Shanley K, Yunis EJ. HLA antigens in mucocutaneous lymph node syndrome in New England. Pediatrics. 1981;67:741-3.

20. Cotch MF, Fauci AS, Hoffman GS. HLA typing in patients with Wegener granulomatosis. Ann Intern Med. 1995;122:635.

21. Hughes T, Coit P, Adler A, Yilmaz V, Aksu K, Düzgün N, et al. Identification of multiple independent susceptibility loci in the HLA region in Behcet's disease. Nat Genet. 2013;45:319-24.

22. Peru H, Soylemezoglu O, Gonen S, Cetinyurek A, Bakkaloğlu SA, Buyan N, et al. HLA class 1 associations in Henoch Schonlein purpura: increased and decreased frequencies. Clin Rheumatol. 2008;27:5-10.

\section{Submit your next manuscript to BioMed Central and take full advantage of:}

- Convenient online submission

- Thorough peer review

- No space constraints or color figure charges

- Immediate publication on acceptance

- Inclusion in PubMed, CAS, Scopus and Google Scholar

- Research which is freely available for redistribution 